\title{
Cross-Talk Between Obesity and Central Nervous System: Role in Cognitive Function
}

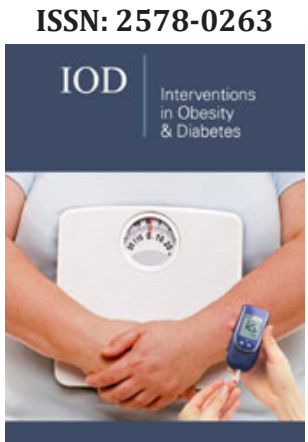

*Corresponding author: Ricardo Augusto Leoni de Sousa, Programa Multicêntrico de Pós-Graduação em Ciências Fisiológicas, Centro Integrado de PósGraduação e Pesquisa em Saúde-CIPqSaúde, Universidade Federal dos Vales do Jequitinhonha e Mucuri (UFVJM), Brazil

Submission: 眥 April 04,2019

Published: 制 June 11, 2019

Volume 3 - Issue 1

How to cite this article: Sousa RAL, Freitas DA and Leite HR. Cross-Talk Between Obesity and Central Nervous System: Role in Cognitive Function. Interventions Obes Diabetes. 3(1). IOD.000551.2019.

DOI: 10.31031/IOD.2019.03.000551

Copyright@ Ricardo Augusto Leoni de Sousa, This article is distributed under the terms of the Creative Commons Attribution 4.0 International License, which permits unrestricted use and redistribution provided that the original author and source are credited.

\author{
Sousa RAL*, Freitas DA and Leite HR \\ Programa Multicêntrico de Pós-Graduação em Ciências Fisiológicas, Brazil
}

\begin{abstract}
Obesity is a world health problem. Excess of white adipose tissue (WAT) might lead to development of neurodegenerative disorders. WAT contributes to low-grade inflammation leading to the enhancement of pro-inflammatory adipokines, such as TNF- $\alpha$, leptin and IL-6, which will lead to a peripheral inflammation that affects central nervous system functioning. Pro-inflammatory adipokines are enhanced in obesity, while anti-inflammatory, such as IL-10 and adiponectin, are reduced. Obesity seems to be related to cognitive decline and the development of neurodegenerative diseases, such as dementia and Alzheimer, through the production of pro-inflammatory adipokines with a consistent reduction of adiponectin and IL-10.
\end{abstract}

Keywords: Obesity; Inflammation; Leptin; Brain regions; Cognitive performance

Abbreviations: WAT: White Adipose Tissue; TNF- $\alpha$ : Tumor Necrosis Factor Alpha; IL: Inter Leukin; CNS: Central Nervous System; BBB: Blood Brain Barrier

\section{Introduction}

Obesity is a health problem in western societies being usually associated with low-grade inflammation [1]. White adipose tissue (WAT) accumulation contribute to an increased risk of obese subjects develop several related diseases, such as type 2 diabetes and neurodegenerative diseases [2-4]. Obesity is associated to mild cognitive impairment, and increased risk of developing dementia and Alzheimer's disease [5,6]. Obesity-induced neuroinflammation has shown to affect brain areas related to cognitive performance and memory, such as the hippocampus, and cortex $[7,8]$. The expanded hazard for obese subjects to develop a CNS pathology mirrors the connectivity of WAT to the cerebrum through different pathways to affect the mind work [4-6]. It is now well established that WAT is not just a fat storage organ, as it was considered for many years, but an endocrine organ that secretes different substances called adipokines, which play a role in cognitive function $[6,9,10]$.

Adipokines circulating levels are changed in overweight, and obesity due to the expansion of WAT $[6,9]$. Low-grade inflammation state is produced by the increased level of several pro-inflammatory adipokines, such as leptin, tumor necrosis factor alpha (TNF- $\alpha$ ), and interleukin (IL)-6 [11]. The levels of circulating pro-inflammatory mediators can affect the central nervous system (CNS) through lymphatic vessels, coroid-plexus and blood brain barrier (BBB) [1]. The mechanism of affecting CNS occurs due to the development of a peripheral inflammation that leads to the elevation of these pro-inflammatory adipokines, such as TNF- $\alpha$, leptin and IL- 6 , which are able to cross the BBB, and might contribute to the development of brain inflammation and insulin resistance $[10,12,13]$. Intracellular signaling mediated by pro-inflammatory adipokines and insulin resistance are the main mediators of obesity-associated cognitive decline because they will disturb synaptic plasticity, induce oxidative stress and neuroinflammation interfering in the learning processes [7,10,14,15]. On the other hand, anti-inflammatory adipokines are diminished in obese individuals, such as IL-10 and adiponectin [6]. 


\section{Leptin resistance in obesity affects learning and memory}

Neurophysiological functions have also been attributed to leptin, another adipokine secreted by WAT that can cross the BBB, which is involved in brain development, neurogenesis, neuronal survival, and behavior [16,17]. In the absence of leptin in early life, even for a short period of time, will favor a poor development of arcuate nucleus neural projection [18]. Leptin also influences reproduction and metabolism acting on the hypothalamus to suppress food intake [16]. Leptin acts as a potential psychological enhancer as it stimulates the cell events involving learning and memory in hippocampi [17]. Leptin responses are diminished in obesity, aging, and neurodegenerative disorders, contributing to insulin resistance and inflammation, and leading to cognitive decline [6]. When leptin is reduced in the organism, we call this physiological change of leptin resistance.

\section{TNF- $\alpha$ is a strong mediator of neuroinflammation and cognitive decline}

Microglial cells and astrocytes are the main TNF- $\alpha$ producers in human body [19]. Neuroinflammation is strongly mediated by microglial and astrocyte cells activation with consequently secretion of TNF- $\alpha$ [20-22]. Learning and memory failure are associated to inflammation and changes in insulin signaling in the brain $[15,23]$. Brain regions involved in cognitive decline show exacerbated microglial and astrocyte expression [5,10,24]. Higher expression of TNF- $\alpha$ with activation of stress kinases are the main features for defective neuronal insulin signaling and, consequent, cognitive decline $[10,25]$. Interestingly, blockade of TNF- $\alpha$ in mouse models leads to an improvement in insulin sensitivity and glucose homeostasis rescuing synaptic plasticity, short and long-term memory $[10,26,27]$.

\section{IL-6 is associated with cognitive decline}

It has been shown that obesity leads to brain atrophy, reducing volume in a number of brain regions [28,29]. Thus, peripheral inflammation might contribute to cognitive decline and memory loss [5]. A recent meta-analysis showed that increased plasma levels of IL- 6 and C-reactive protein are main features of obesity that are associated with an increase in dementia [30]. However, a recent study revealed that IL- 6 blockade increased cholesterol levels, and visceral adipose tissue was not reduced even under physical exercise training [31]. Thus, IL-6 is needed for exercise in order to reduce visceral adipose tissue mass and also play an undefined role in cognitive decline [30,31].

\section{IL-10 reduces neuronal degeneration}

Termination of neuroinflammation has the participation of antiinflammatory adipokines, such as IL-10 [32]. It has been shown that the level of IL-10 in different areas of the brain increases in several conditions and diseases, thereby promoting survival of neurons [33-35]. Associations between cognitive decline, memory loss and pro-inflammatory adipokines have been showed and the oppose actions to these mechanisms by IL-10 have also been proved in a recent meta-analysis [35]. It can be suggested that antiinflammatory cytokines, such as IL-10, develop an important role in conditions of memory impairment, since IL-10 is also synthesized in the central nervous system [32-35].

\section{Adiponectin reduction is related to memory impairment}

Adiponectin is responsible for the increasing in insulin sensitivity in liver and muscle [36]. Adiponectin develops several anti-inflammatory activities, such as suppression of macrophage activation, in peripheral tissues [37]. It inhibits, in vivo and in vitro, microglia pro-inflammatory profile [38]. Plasma levels of adiponectin are decreased in obesity and contribute to insulin resistance being also linked to cardiovascular diseases [39]. Low levels of adiponectin are also related to cognitive decline, although the specific role in brain functioning related to learning and memory is not completely clarified yet.

\section{Conclusion}

Obesity is a world health problem that has been linked to a reduction in cognitive performance. Obese subjects present an increased risk to develop neurodegenerative disorders, such as type 2 diabetes, dementia, and Alzheimer. Excess of white body fat tissue seems to lead to neuroinflammation through activation of different adipokines affecting cognitive performance and memory. The ability of adipokines, pro and anti-inflammatory, to modulate learning and memory emphasizes the special properties of the WAT not only in obesity.

\section{References}

1. Guillemot LO, Muccioli GG (2017) Obesity-induced neuroinflammation: Beyond the hypothalamus. Trends Neurosci 40(4): 237-253.

2. Walsh JJ, D’Angiulli A, Cameron JD, Sigal RJ, Kenny GP, et al. (2018) Changes in the brain-derived neurotrophic factor are associated with improvements in diabetes risk factors after exercise training in adolescents with obesity: The HEARTY randomized controlled trial. Neural Plast 1-8.

3. Musi N, Guardado MR (2014) Adipose tissue as an endocrine organ. Cell Endocrinol Heal Dis 89(6): 229-237.

4. Camargos ACR, Mendonça VA, Oliveira KSC, de Andrade CA, Leite HR, et al. (2017) Association between obesity-related biomarkers and cognitive and motor development in infants. Behav Brain Res 325: 12-16.

5. Nguyen JCD, Killcross AS, Jenkins TA (2014) Obesity and cognitive decline: Role of inflammation and vascular changes. Front Neurosci 8(OCT): $1-9$.

6. Forny GL, De Felice FG, Vieira MN (2019) The role of leptin and adiponectin in obesity-associated cognitive decline and Alzheimer's disease. Front Neurosci 12(January): 1-19.

7. Johnson LA, Zuloaga KL, Kugelman TL, Mader KS, Morré JT, et al. (2016) Amelioration of metabolic syndrome-associated cognitive impairments in mice via a reduction in dietary fat content or infusion of non-diabetic plasma. EBioMedicine 12(3): 26-42.

8. Petrov D, Pedrós I, Artiach G, Sureda FX, Barroso E, et al. (2015) Highfat diet-induced deregulation of hippocampal insulin signaling and mitochondrial homeostasis deficiences contribute to Alzheimer disease pathology in rodents. Biochim Biophys Acta-Mol Basis Dis 1852(9): 1687-1699. 
9. Lehr S, Hartwig S, Lamers D, Famulla S, Müller S, et al. (2011) Identification and validation of novel adipokines released from primary human adipocytes. Mol Cell Proteomics 11(1): M111.010504.

10. Lourenco MV, Clarke JR, Frozza RL, Bomfim TR, Forny GL, et al. (2013) TNF- $\alpha$ mediates PKR-dependent memory impairment and brain IRS1 inhibition induced by Alzheimer's $\beta$-amyloid oligomers in mice and monkeys. Cell Metab 18(6): 831-843.

11. Friedemann C, Heneghan C, Mahtani K, Thompson M, Perera R, et al. (2012) Cardiovascular disease risk in healthy children and its association with body mass index: Systematic review and meta-analysis. BMJ 345: e4759.

12. Bomfim TR, Forny GL, Sathler LB, Brito MJ, Houzel J, et al. (2012) An antidiabetes agent protects the mouse brain from defective insulin signaling caused by Alzheimer's disease-associated $A \beta$ oligomers. J Clin Invest 122(4):1339-1353.

13. De Felice FG, Ferreira ST (2014) Inflammation, defective insulin signaling, and mitochondrial dysfunction as common molecular denominators connecting type 2 diabetes to Alzheimer disease. Diabetes 63(7): 2262 2272 .

14. Cottam DR, Mattar SG, Barinas ME, Eid G, Kuller L, et al. (2004) The chronic inflammatory hypothesis for the morbidity associated with morbid obesity: Implications and effect of weight loss. Obes Surg 14(5): 589-600.

15. Sousa RAL, Torres YS, Figueiredo CP, Passos GF, Clarke JR (2018) Consequences of gestational diabetes to the brain and behavior of the offspring. An Acad Bras Cienc 90(2): 2279-2291.

16. Denver RJ, Bonett RM, Boorse GC (2011) Evolution of leptin structure and function. Neuroendocrinology 94(1): 21-38.

17. Doherty GH, Beccano KD, Yan S Du, Gunn MFJ, Harvey J (2013) Leptin prevents hippocampal synaptic disruption and neuronal cell death induced by amyloid $\beta$. Neurobiol Aging 34(1): 226-237.

18. Teixeira PD, Ramos-Lobo AM, De Felice FG, Donato J, Lyra e Silva NM, et al. (2019) Long-term consequences of the absence of leptin signaling in early life. Elife 8: 1-25.

19. Nichols MR, Pierre MK, Wendeln AC, Makoni NJ, Gouwens LK, et al. (2019) Inflammatory mechanisms in neurodegeneration. J Neurochem 149(5): 562-581

20. Soreq L, Rose J, Soreq E, Hardy J, Trabzuni D, et al. (2017) Major shifts in glial regional identity are a transcriptional hallmark of human brain aging. Cell Rep 18(2): 557-570.

21. Hasel P, Dando 0, Jiwaji Z, Baxter P, Todd AC, et al. (2017) Neurons and neuronal activity control gene expression in astrocytes to regulate their development and metabolism. Nat Commun 8: 15132.

22. Chen Z, Trapp BD (2016) Microglia and neuroprotection. J Neurochem Suppl 1:10-17.

23. De Sousa RAL (2018) Gestational diabetes is associated to the development of brain insulin resistance in the offspring. Int J Diabetes Dev Ctries 39(2): 408-416.

24. Tapia RC, Aranguiz F, Varela NL, Inestrosa NC (2016) Voluntary running attenuates memory loss, decreases neuropathological changes and induces neurogenesis in a mouse model of Alzheimer's disease. Brain Pathol 26(1): 62-74.
25. Ferreira ST, Clarke JR, Bomfim TR, De Felice FG (2014) Inflammation, defective insulin signaling, and neuronal dysfunction in Alzheimer's disease. Alzheimer's Dement 10(1): S76-S83.

26. Ferreira ST, Klein WL (2011) The $A \beta$ oligomer hypothesis for synapse failure and memory loss in Alzheimer's disease. Neurobiol Learn Mem 96(4): 529-543.

27. Hotamisligil GS, Spiegelman BM (1994) Tumor necrosis factor alpha: A key component of the obesity-diabetes link. Diabetes 43(11): 12711278.

28. Gustafson D, Lissner L, Bengtsson C, Björkelund C (2004) A 24-year follow-up of body mass. Neurology 63(10): 1876-1881.

29. Taki Y, Kinomura S, Sato K, Inoue K, Goto R, et al. (2008) Relationship between body mass index and gray matter volume in 1,428 healthy individuals. Obesity 16(1): 119-124.

30. Koyama A, O’Brien J, Weuve J, Blacker D, Metti AL, et al. (2013) The role of peripheral inflammatory markers in dementia and Alzheimer's disease: A meta-analysis. Journals Gerontol-Ser A Biol Sci Med Sci 68(4): 433-440.

31. Wedell NAS, Lehrskov LL, Christensen RH, Legaard GE, Dorph EB, et al. (2018) Exercise-induced changes in visceral adipose tissue mass are regulated by IL- 6 signaling: A randomized controlled trial. Cell Metab 29(4): 844-855

32. Arkhipov VI, Pershina EV, Levin SG (2019) The role of anti-inflammatory cytokines in memory processing in a healthy brain. Behav Brain Res 367 111-116.

33. Bachis A, Colangelo AM, Vicini S, Doe PP, De Bernardi MA, et al. (2001) Interleukin-10 prevents glutamate-mediated cerebellar granule cell death by blocking caspase-3-like activity. J Neurosci 21(9): 3104-3112.

34. Golbidi S, Laher I (2014) Exercise induced adipokine changes and the metabolic syndrome. J Diabetes.

35. Swardfager W, Lanctôt K, Rothenburg L, Wong A, Cappell J, et al. (2010) A meta-analysis of cytokines in Alzheimer's disease. Biol Psychiatry 68(10): 930-941

36. Spyridaki EC, Simos P, Avgoustinaki PD, Dermitzaki E, Venihaki M, et al. (2014) The association between obesity and fluid intelligence impairment is mediated by chronic low-grade inflammation. Br J Nutr 112(10): 1724-1734

37. Elfeky M, Yoneshiro T, Okamatsu OY, Kimura K (2018) Adiponectin suppression of late inflammatory mediator, HMGB1-induced cytokine expression in RAW 264 macrophage cells. J Biochem 163(2): 143-153.

38. Nicolas S, Cazareth J, Zarif H, Guyon A, Heurteaux C, et al. (2017) Globular adiponectin limits microglia pro-inflammatory phenotype through an adipoR1/NF-кB signaling pathway. Front Cell Neurosci 11: 1-20.

39. Komatsu M, Ohfusa H, Sato Y, Yajima H, Yamauchi K, et al. (2004) Strong inverse correlation between serum adiponectin level and heart ratecorrected QT interval in an apparently healthy population. Diabetes Care 27(5): 1240 . 